\section{Partial proximal trisomy of the long arm of chromosome 5 (q13 $\rightarrow$ q22) resulting from maternal insertion der ins $(10 ; 5)$}

SUMMARY Five members of our study family were carriers of a balanced insertion $(10 ; 5)$ (q22;q13q22). One of the children had psychomotor retardation and malformations resulting from a partial trisomy of the proximal long arm of chromosome 5, having received the maternal der(10). Amniocentesis identified another case of partial proximal trisomy in a fetus of a subsequent pregnancy. This clinical and family study is compared with two other published cases of proximal trisomy 5q.

A fairly large number of cases of partial trisomy $5 p$ have been published and the corresponding clinical syndrome described. Cases of trisomy $5 q$ are rare and usually involve the terminal region. Only two cases of proximal trisomy $5 \mathrm{q}$ have been published, ${ }^{12}$ one being the result of maternal insertion, ${ }^{1}$ as in our case.

In this report, we will present our clinical findings and the family history and correlate our study with other published case studies of partial trisomy 5q.

\section{Case report}

\section{CLINICAL DESCRIPTION}

The proband (III $\cdot 1$ ) was born at term on 26 January 1976 to unrelated parents. The mother was 22 years old and the father was 25 . During pregnancy we noted retardation of fetal development, the uterine length being $30 \mathrm{~cm}$ at term. At birth, the baby weighed $2300 \mathrm{~g}$ and examination of the placenta showed discrete villous hypotrophy. Apgar score was 4 at 1 minute and 9 at 5 minutes.

From the beginning, we noted a dysmorphic syndrome. Head circumference was $33 \mathrm{~cm}$ with a thoracic circumference of $28.5 \mathrm{~cm}$ and a height of $46 \mathrm{~cm}$. The microcephaly was accompanied by facial dysmorphia with protrusion of the middle level of the face, protruding upper dental arch, vaulted palate, retracted chin, and discrete epicanthus, Received for publication 10 January 1981



FIG 1 Proband $(I I I \cdot 1)$ at the ages of 5 months (above) and 4 years (below).

mostly inferiorly (fig 1). A coccygeal pit was also present. The clinical examination revealed hypertonia of the lower extremities and a systolic mesocardial murmur. Subsequently, the psychomotor and growth retardation became more pronounced. The microcephaly corresponded to approximately -4 SD.

We saw the patient again at the age of 4 . The child's weight was $9 \cdot 1 \mathrm{~kg}$ ( $-4 \mathrm{SD})$, height $89 \mathrm{~cm}$ $(-3 \cdot 5 \mathrm{SD})$, and head circumference $42 \mathrm{~cm}(-5 \mathrm{SD})$. Besides the upper maxillary protrusion, the vaulted palate, and the epicanthus, the facial dysmorphism included an antimongoloid slant, 'comma' eyebrows with a thickened base and narrowed extremity, and asymmetrical ears with a thickened helix on the right ear and a poorly differentiated helix on the left ear. 
The neurological examination revealed hypotonia of the trunk in contrast to hypertonia of the lower extremities and considerable generalised amyotrophy. Cardiovascular examination revealed a $2 / 6$ systolic murmur over the aortic area. The characteristics of the murmur and follow-up echocardiography led us to suspect hypoplasia of the ascending aorta without other associated abnormalities. Psychomotor development at the age of 4 years 2 months corresponded to a normal 9 month developmental level. The child was incontinent, did not talk, walk, or respond to her name. She ambulated on all fours and could sit by herself. She was happy and smiling and played with toys. Radiological examination revealed no abnormalities other than scoliosis. The bone age $\stackrel{\square}{?}$ was between 5 years 9 months and 6 years 10 months $\overrightarrow{\bar{F}}$ (ulnar epiphyseal point).

Dermatoglyphs showed five arches on the fingertips and bilateral $t^{\prime}$ axial triradii.

\section{CYTOGENETIC STUDY}

From lymphocyte culture, it was determined that the karyotype was $46, \mathrm{XX}, 10 \mathrm{q}+$.The QFQ, GTG, and $\vec{\circ}$ RBA techniques did not permit identification of the nature of the genetic material (fig 2). The same $\vec{\omega}$ abnormality was found in fibroblast cultures. A

TABLE Clinical and cytogenetic findings in 15 cases of distal trisomy $5 q$ and 4 cases of proximal trisomy $5 q$

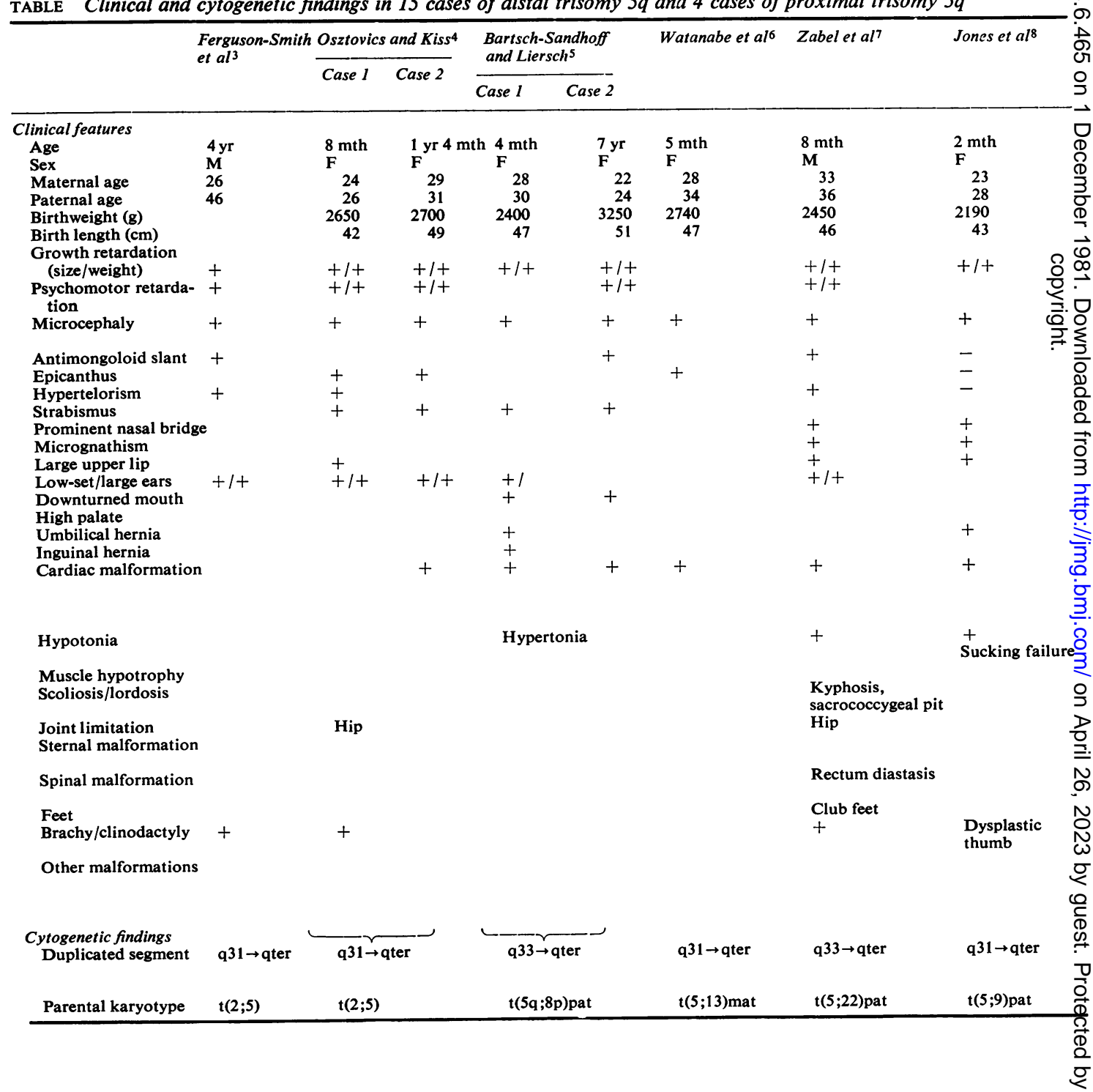


cytogenetic study was done on the parents, but there was no evidence of any abnormality.

\section{FAMILY HISTORY}

In 1974 the first pregnancy ended after 4 weeks. In 1976 a second spontaneous abortion took place in the 5 th week of pregnancy. No study was undertaken on the abortus. In 1977 an amniocentesis was done during the fourth pregnancy, because of the family history, despite apparently normal parental karyotypes. A 46,XX,10q + karyotype, identical to that of the proband, was discovered (fig 3). Abortion was undertaken. The fetus of female sex was $31 \mathrm{~cm}$ long and weighed $700 \mathrm{~g}$. There was craniofacial dysmorphism with hypertrophy of the upper dental arch, microretrognathism, and an antimongoloid slant. We noted hyperlaxity of the ligaments of the 5th left toe and an internal deviation with overlapping on the 4th left toe. Anatomical studies revealed a cardiac malformation of large vessel transposition and interventricular septal defect associated with pulmonary atresia and isthmic stenosis.

The parental karyotypes were then carefully restudied. In the mother we discovered a direct balanced insertion of the long arms of chromosome

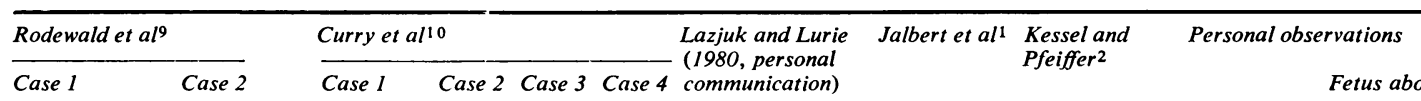

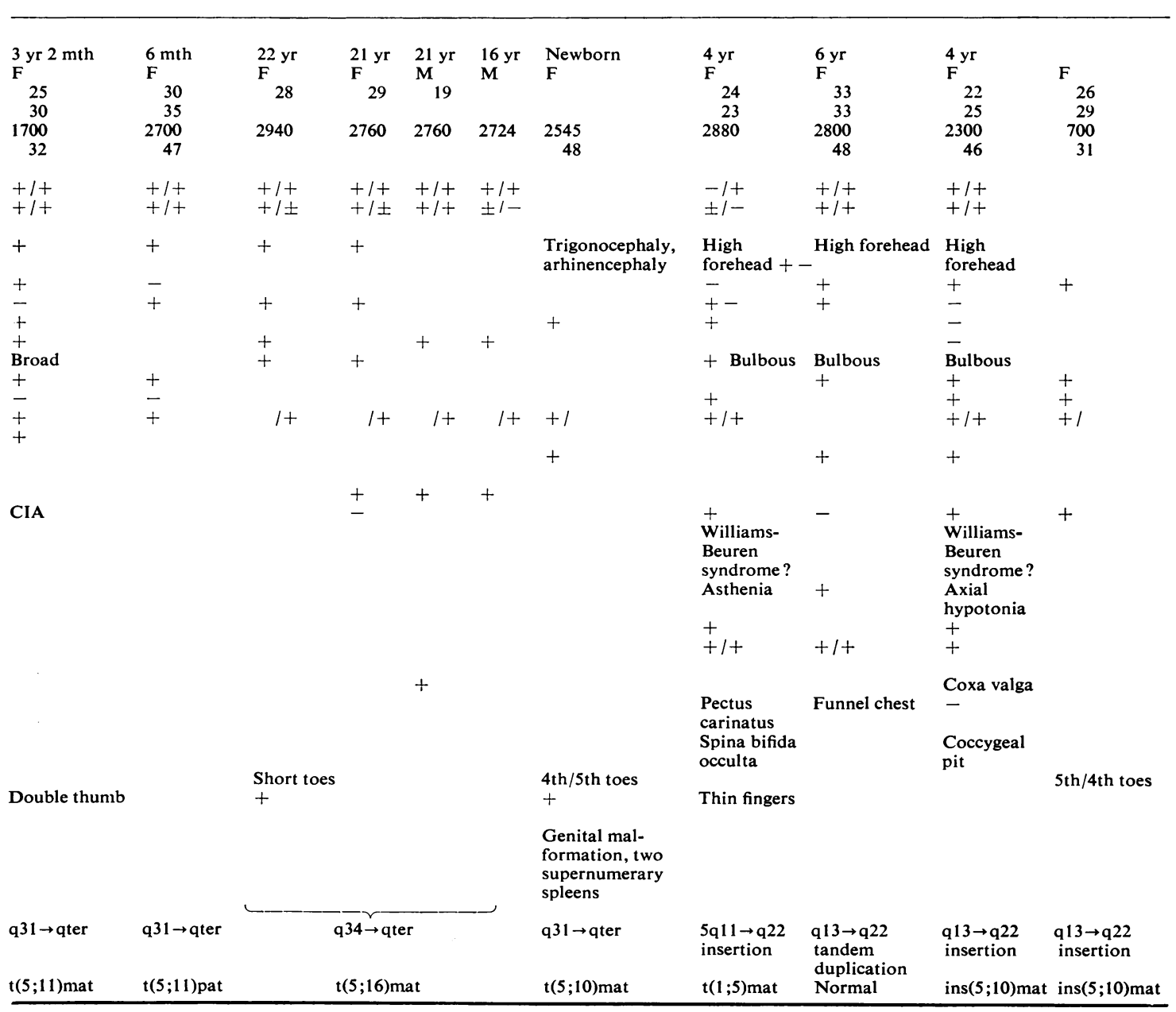




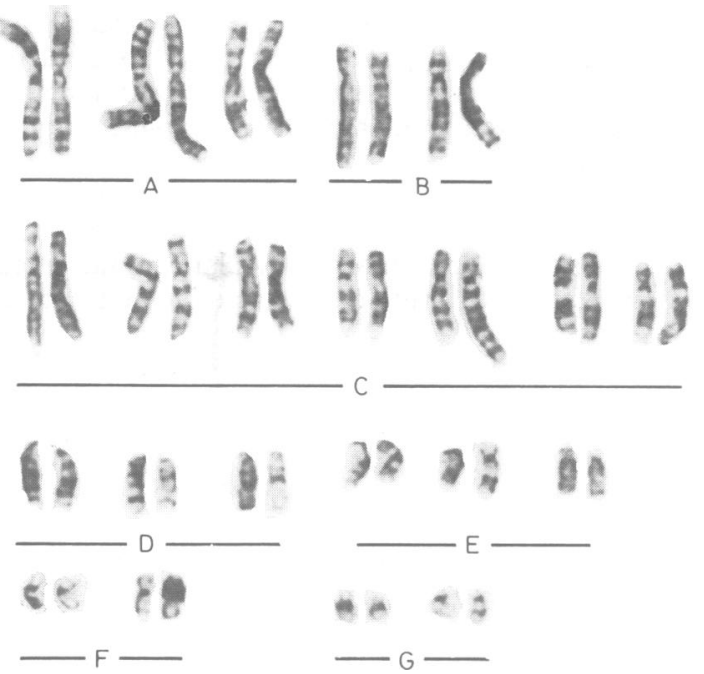

10
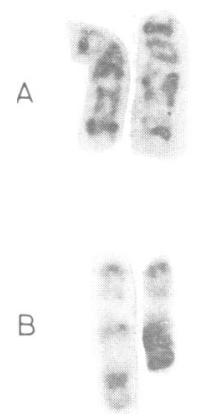

FIG 3 A, fetus (III -2): chromosomes 5 and 10 (GTG banding); $B$, mother (II $\cdot 1)$ : chromosomes 5 and 10 ( $R H G$ banding).

5 into the long arms of chromosome 10 (fig 3). After QFQ, GTG, RHG, and RBG studies, we concluded that the karyotype was $46, X X$, dir ins $(10 ; 5)(\mathrm{q} 22 ; \mathrm{q} 13$ q22) (fig 4). The proband and the fetus were $46, X X,-10,+\operatorname{der}(10)$ ins $(10$ pter $\rightarrow 10 \mathrm{p} 22:: 5 \mathrm{p} 135 \mathrm{q} 22$ $:: 10 \mathrm{q} 23 \rightarrow 10 \mathrm{qter}) \mathrm{mat}$. Hence they were trisomic for $5 q$ from $5 q 13$ to $5 \mathrm{q} 22$. The family pedigree showed that the balanced insertion was present in the grandmother $(\mathbf{I} \cdot 1)$ of the proband, in her uncle (II-3), and in her aunt (II·6) (fig 5).

Lastly, in 1979, amniocentesis showed that the karyotype of the current pregnancy was a normal 46,XY. On 11 December 1979 a normal boy weighing $4200 \mathrm{~g}$ and $54 \mathrm{~cm}$ in length was born and his subsequent development was perfectly satisfactory.
FIG 2 Karyotype of proband (III.1) (GTG banding).

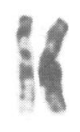
$\dot{\vec{\infty}}$

家

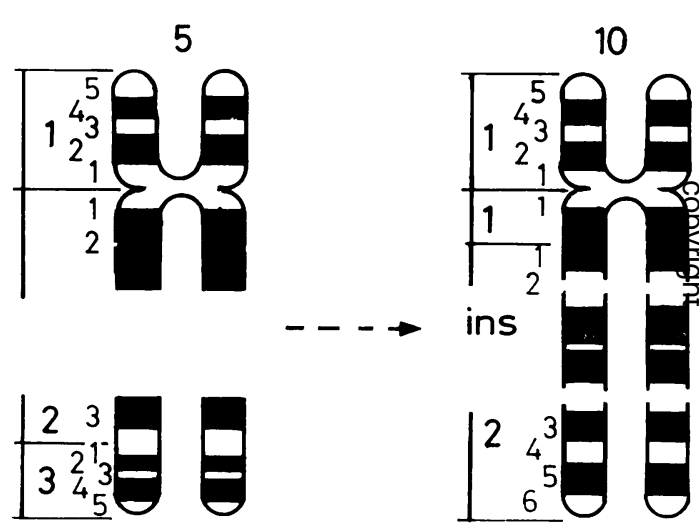

FIG 4 Diagram of $G$ banding of mother $(I I \cdot 1)$ with ins $(10 ; 5)(10$ pter $\rightarrow 10 q 22:: 5 q 13 \rightarrow 10$ qter $; 5$ pter $\rightarrow 5 q 13::$ $5 q 23 \rightarrow 5 q t e r)$.

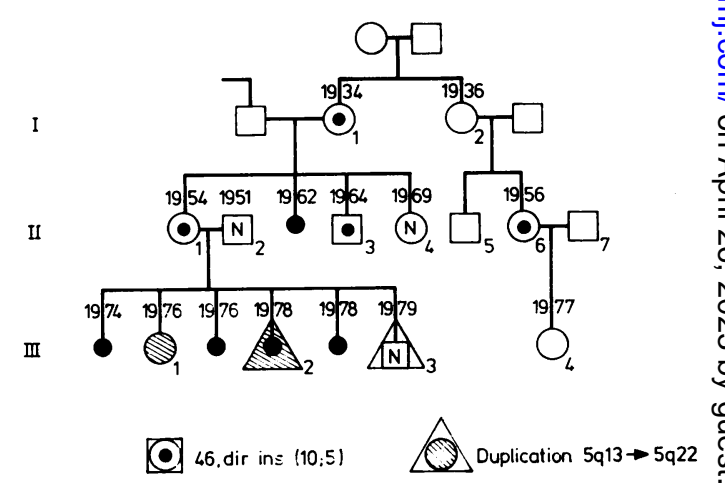

FIG 5 Family pedigree. 


\section{Discussion}

We have accumulated 19 cases of partial trisomy $5 q$ (table) including 15 girls and four boys.

In 15 cases, the trisomy was distal and resulted from a balanced parental translocation between a chromosome 5 and the following chromosomes: 2 (twice), 8, 9, 10, 11, 16, 19, and 27. Rodewald et al subdivided the distal trisomies $5 \mathrm{q}$ into two groups according to clinical and cytogenetic findings. One group was that in which the duplicated segment was from 5q31 to 5qter (6 cases) (Lazjuk and Lurie, 1980, personal communication) $)^{i} 4689$ and from $5 \mathrm{q} 33$ to 5 qter $\left(3\right.$ cases). ${ }^{5} 7$ They have in common the foilowing clinical symptoms: low birthweight, psychomotor retardation, brady- and clinodactyly, as well as facial dysmorphism, strabismus, epicanthus, a protruding nose base and prolongation of the forehead, oversized top lip, and large protruding ears. Only one child (Lazjuk and Lurie, 1980, personal communication), who died 2 hours after birth, had genital and severe nervous system malformations.

A second group was that in which the duplicated segment included only the bands from $5 \mathrm{q} 34$ to $5 \mathrm{qter}^{10}$ and in which the clinical symptomatology was less severe, including only hypotrophy and strabismus.

Proximal trisomy $5 \mathrm{q}$ was demonstrated in four cases if the fetus is included. The duplicated segment ranged from $5 \mathrm{q} 11^{4}$ or $5 \mathrm{q} 13$ to $5 \mathrm{q} 22$ (our observation). ${ }^{8}$

Two families exhibited insertion, while one other family exhibited tandem duplication. These two types of abnormalities are relatively rare.

The three girls had (besides psychomotor retardation) comparable facial dysmorphism including high forehead with median vaulting, bulbous nose with nostrils oriented downwards, externally flattened supraorbital margin and falling eyebrows, short philtrum and protruding upper lip without Cupid's arch, malpositioned teeth, small chin, and large protruding ears. They also presented skeletal abnormalities (sternum, spine) and muscular hypotrophy.

Dermatoglyphic patterns have in common arches on the fingertips and bilateral $t^{\prime}$ axial triradii in two cases. No simian crease was observed.

In two cases, the cardiopathy associated with the facial dysmorphism was similar to Williams-Beuren syndrome. The pulmonary atresia with an open ventricular septum observed in the fetus can be considered an extreme form of malformation of the ejection channels of the heart.

In conclusion, apart from already described distal 5q trisomies, ${ }^{9}$ it seems at last possible to describe a syndrome corresponding to duplication of a proximal segment $5 \mathrm{q} 13$ to $5 \mathrm{q} 22$. Further investigations are necessary to describe this syndrome more precisely.

We thank Professors R Pfeiffer and B Sele for sending pictures and dermatoglyphs of their case and Mme B Petitjean for her skilful technical assistance.

S Gilgenkrantz,* P DulucQ, $\dagger$ J L Bresson, A Gouget, $\ddagger$ C Pernot,§ AND M J Gregolre* *Centre de Transfusion Sanguine de Nancy, Laboratoire de Cytogénétique, Avenue de Bourgogne, 54500 Vandoeuvre Les Nancy; $\dagger$ Centre Hospitalier Général de Remiremont, Service de Pédiatrie, 88200 Remiremont; $\ddagger$ Centre Hospitalier Universitaire Saint Jacques (Pr Bugnon), Laboratoire de Cytogénétique, 25030 Besancon Cedex; and $\S$ Centre Hospitalier Régional, Hôpital Jeanne d'Arc, Service de Cardiologie Infantile, 54201 Toul Cedex, France

\section{References}

1 Jalbert P, Jalbert H, Sele B, et al. Partial trisomy for the long arms of chromosome No 5 due to insertion and further 'aneusomie de recombinaison'. I Med Genet $1975 ; 12: 418-23$.

2 Kessel E, Pfeiffer RA. Tandem duplication $(5 q 13 \rightarrow 22)$ in a mentally deficient girl. Hum Genet 1979;52:217-20.

3 Ferguson-Smith MA, Newman BF, Ellis PM, Thomson DMG, Riley IO. Assignment by deletion of human red cell acid phosphatase gene locus to the short arm of chromosome 2 . Nature $1973 ; 243: 271-4$.

4 Osztovics M, Kiss P. Familial translocation, $t(2 ; 5)$ (p28;q31) Clin Genet 1975;8:112-6.

5 Bartsch-Sandhoff M, Liersch R. Partial duplication $5 q$ syndrome. Phenotypic similarity in two sisters with identical karyotype (partial duplication 5 q33 $\rightarrow 5$ qter and partial deficiency 8 p23 $\rightarrow$ pter). Ann Genet (Paris) 1977;20: 281-4.

6 Watanabe G, Kiyoi Y, Takeyama I, Kawana S, Yamamoto $\mathbf{H}$. Inherited chromosomal translocation in two families $\mathrm{t}(4 \mathrm{q}-; 13 \mathrm{q}+)$ and $\mathrm{t}(5 \mathrm{q}-; 13 \mathrm{q}+)$. Tohoku $J$ Exp Med 1977;121:179-84.

7 Zabel B, Baumann W, Gehler J, Conrad G. Partial trisomy for short and long arm of chromosome No 5. Two cases of two possible syndromes. J Med Genet $1978 ; 15: 143-7$.

8 Jones LA, Jordan DK, Taysi K, Strauss AW, Toth JK. Partial duplication of the long arm of chromosome 5: a case due to balanced paternal translocation and review of the literature. Hum Genet $1979 ; 51: 37-42$.

9 Rodewald A, Kankl M, Gley EO, Zang KD. Partial trisomy 5q: three different phenotypes depending on different duplication segments. Hum Genet 1980;55:191-8.

10 Curry C Jr, Loughman WD, Francke U, Bryan DH, Golbus MS, Derstine J, Epstein CJ. Partial trisomy for the distal long arm of chromosome 5 (region $\mathrm{q} 34 \rightarrow \mathrm{qter}$ ). A new clinically recognizable syndrome. Clin Genet $1979 ; 15: 454-61$.

Requests for reprints to Dr Simone Gilgenkrantz, Laboratoire de Cytogénétique, Centre de Transfusion Sanguine de Nancy, Avenue de Bourgogne, 54500 Vandoeuvre, France. 